\section{$\underset{\substack{\text { hommes } \\ \text { \& migrations }}}{ }$}

\section{Hommes \& migrations}

Revue française de référence sur les dynamiques

migratoires

$1284 \mid 2010$

Migrations et environnement

\title{
Eddy Vaccaro et Aurélien Ducoudray, Championzé
}

Édition Futuropolis, 2010, 127 pages, 20 euros

\section{Mustapha Harzoune}

\section{(2) OpenEdition}

1 Journals

\section{Édition électronique}

URL : http://journals.openedition.org/hommesmigrations/1284

DOI : 10.4000/hommesmigrations. 1284

ISSN : 2262-3353

\section{Éditeur}

Musée national de l'histoire de l'immigration

\section{Édition imprimée}

Date de publication : 1 mars 2010

Pagination : 208-209

ISSN : 1142-852X

\section{Référence électronique}

Mustapha Harzoune, «Eddy Vaccaro et Aurélien Ducoudray, Championzé », Hommes \& migrations [En

ligne], 1284 | 2010, mis en ligne le 29 mai 2013, consulté le 24 septembre 2020. URL : http:// journals.openedition.org/hommesmigrations/1284 ; DOI : https://doi.org/10.4000/

hommesmigrations. 1284

Ce document a été généré automatiquement le 24 septembre 2020.

Tous droits réservés 


\title{
Eddy Vaccaro et Aurélien Ducoudray, Championzé
}

Édition Futuropolis, 2010, 127 pages, 20 euros

\author{
Mustapha Harzoune
}

\section{RÉFÉRENCE}

Eddy Vaccaro et Aurélien Ducoudray, Championzé, Édition Futuropolis, 2010, 127 pages, 20 euros

1 Qui pourrait aujourd'hui imaginer le sport tricolore sans ses athlètes noirs? Un rapide survol et voilà que les Blacks de France font résonner les cocoricos du coq gaulois urbi et orbi. Au football bien sûr, mais aussi sur les stades d'athlétisme, dans les arts martiaux, le basket-ball, le handball, le volley et depuis peu le rugby. Le tennis reprend des couleurs grâce à Monfils et à Tsonga, héritiers de l'illustre Yannick Noah. La liste, bien sûr, n'est pas exhaustive. Pourtant, il y a tout juste trois ans, la Licra publiait un rapport où elle s'inquiétait des "dérives racistes" dans le sport, et tout spécialement dans le football! Le racisme et le sport, voilà un couple qui a la vie dure et les choses ne semblent pas s'améliorer à la vue des différentes affaires qui défraient la chronique sportive ces dernières années.

2 Qui connaît celui qui fut le premier champion français noir? Il s'appelait Amadou M'Barick Fall, surnommé Siki, il fut champion du monde de boxe le 24 septembre 1922. 1922 ! L'année où le Marocain Abd-el Krim proclamait l'indépendance du Rif. L'année aussi où la France, reconnaissante pour ses soldats musulmans tombés durant la Première Guerre mondiale, entame la construction de la Mosquée de Paris. Amadou M'Barick Fall en était, lui, du champ de bataille, et du genre courageux, médaillé de la Croix de guerre et du mérite.

3 Mais voilà donc que ce Noir, français, puisque né à Saint-Louis du Sénégal en 1897, alors sous domination française, musulman qui ne dédaignera pas plus tard la bouteille, enverra au tapis, au sixième round grâce à un uppercut appuyé, l'idole et la fierté 
nationales: Georges Carpentier lui-même, ci-devant champion du monde, à la peau majestueusement blanche devant l'Éternel! Un "cataclysme" selon le mot de JeanMarie Bretagne qui consacra une biographie à Siki il y a quelques années ${ }^{1}$. Un cataclysme tel dans la France coloniale que l'arbitre de la rencontre prétendra que Battling Siki aurait... triché. Allez savoir pourquoi, les quarante mille spectateurs qui assistaient à la rencontre à Montrouge protestèrent! Et bruyamment ! Contraignant l'arbitre à accorder la victoire à qui de droit.

Battling Siki atteint donc la plus haute marche. Pour son plus grand malheur. Car à l'époque on ne plaisante pas avec la suprématie de la "race" blanche sur la "race" noire »! D'autant plus que celui qu'on surnomme "Championzé", autrement dit "le champion des chimpanzés", refuse de jouer le jeu. N'ayant plus rien à attendre du Vieux Continent, il file aux États-Unis espérant affronter Jack Dempsey, le champion du monde poids lourds. Il y subira les mêmes attaques, les mêmes sarcasmes et on lui refusera le droit de boxer. Battling Siki ne baisse pas la garde et chatouille là où ça fait mal : "Vous avez une statue de la Liberté ici, mais c'est un mensonge." Il se rebiffe et en remontre aux racistes de tous poils, il multiplie les provocations, et suprême sacrilège, épouse une seconde femme, blanche bien sûr.

C'est cette histoire que viennent de mettre en bande dessinée Eddy Vaccaro (pour les dessins) et Aurélien Ducoudray (pour le texte). Ils suivent au plus près le parcours exceptionnel de ce gamin du Sénégal, ce Français des colonies, abattu dans une rue de New York en 1925. Efficaces, les textes et les dessins s'attachent à rendre l'atmosphère d'une époque, l'injustice subie, les torts infligés, les remugles nauséeux d'un Occident qui prétendait apporter la civilisation au reste du monde! Tout cela est fait sans forcer le trait. De manière légère, fluide, sans pesanteur idéologique ni accusation. Le coup de crayon est alerte, multiplie les sujets et planches originales.

6 À l'heure où le corps du champion françaisest expédié à la morgue de Harlem, Pétain mate la rébellion des Berbères du Rif à l'ypérite, la Mosquée de Paris finit de se construire dans un Paris de l'entre-deux-guerres qui commence à s'enthousiasmer pour une nouvelle idole : Joséphine Baker.

\section{NOTES}

1. Jean-Marie Bretagne, Battling Siki, Éditeur Philippe Rey, coll. “À Tombeau Ouvert”, 2008. 